\title{
Joint attention, joint action, and participatory sense making
}

\section{Shaun Gallagher}

\section{(2) OpenEdition \\ Journals}

Electronic version

URL: http://journals.openedition.org/alter/1637

DOI: $10.4000 /$ alter.1637

ISSN: 2558-7927

Publisher:

Association ALTER, Archives Husserl (CNRS-UMR 8547)

\section{Printed version}

Date of publication: 1 October 2010

Number of pages: 111-123

ISBN: 2-9522374-6-8

ISSN: $1249-8947$

\section{Electronic reference}

Shaun Gallagher, « Joint attention, joint action, and participatory sense making », Alter [Online], 18। 2010, Online since 01 June 2020, connection on 29 June 2020. URL : http://journals.openedition.org/ alter/1637 ; DOI : https://doi.org/10.4000/alter.1637 


\title{
JOINT ATTENTION, JOINT ACTION, AND PARTICIPATORY SENSE MAKING ${ }^{1}$
}

\author{
Shaun Gallagher
}

Developmentally, joint attention is located at the intersection of a complex set of capacities that serve our cognitive, emotional and actionoriented relations with others. It forms a bridge between primary intersubjectivity and secondary intersubjectivity (Trevarthan 1978, 1998; Trevarthan and Hubley 1979). Primary intersubjectivity consists in a set of sensory-motor abilities that allow us to understand the meaning of another person's movements, gestures, facial expressions, eye direction, and intentional actions, in the context of face-to-face interactions. These are the abilities that we first require in order to enter into joint-attentional situations. Once we are in situations of joint attention we are then able to further enhance our understanding of others, in secondary intersubjectivity, by seeing how they use things and how our shared world forms a context for their actions ${ }^{2}$.

1. For work on this project I have benefited from research grants at the École normale supérieure de Lyon and CNRS while a visiting professor at the ENS in Lyon (2010), and visiting researcher at the Centre de recherche en épistémologie appliquée, École polytechnique, Paris (2009 and 2010). An earlier version of this paper was presented at the Husserl Archives at the École normale supérieure in Paris.

2. The concepts of primary and secondary intersubjectivity were first explicated in developmental studies. These are not, however, stages or precursors that we go through and that we eventually leave behind (cf. Baron-Cohen 1991). Rather, the various capacities of primary and secondary intersubjectivity, including joint attention, continue to characterize our adult interactions. That is, as adults, we continue to rely on embodied capabilities that facilitate our primary-intersubjective understanding of others through our perception of their postures, facial expressions, actions, etc., and our secondary-intersubjective capacities to engage with them in highly contextualized situations (see Gallagher 2005; 2008a\&b). The interaction theory of social cognition, in contrast to theory-of-mind approaches ("theory theory" or simulation theory) adds communicative and narrative competencies to these embodied abilities to explain the more nuanced and sophisticated practices that characterize our adult understandings. 
Joint attention contributes to two important aspects of intersubjectivity: (1) social cognition, our ability to understand others, what they intend, and what their actions mean; and (2) participatory sense-making, our ability to understand the world through our interactions with others (De Jaegher and Di Paolo 2007; De Jaegher, Di Paolo and Gallagher, 2010; Gallagher 2009). Participatory sense-making (PSM) is, our ability to co-constitute (with others) meaning in different contexts and environments. In this paper I explore how joint attention contributes to PSM, and how the coordination involved in joint attention and joint action involve embodied and distributed cognitive processes.

The question addressed here is whether joint attention is to be understood in terms of the coordination of mental states between individuals, as the standard theory-of-mind approaches to social cognition contend. On these approaches, including both theory theory (TT) and simulation theory (ST), the idea is that joint attention involves a kind of "mindreading" that depends on theoretical inference or simulation of the other person's mental states. I understand your intentions and what you are going to do by understanding your beliefs and desires. The alternative view, defended by interaction theory (IT), is that joint attention is based primarily on embodied, enactive, and extended interactive processes. That is, the coordination involved in joint attention and joint action is primarily one constituted by embodied movement, gestures, facial expressions, and communicative practices, located in specific contexts. From just such interactive situations, we co-constitute the meaning of the other person's actions and the world around us.

\section{Social cognition and participatory sense-making}

The problems of social cognition (how we understand others) and PSM (how we understand the surrounding world with or through others) are closely related, but they are in fact two different problems (Gallagher 2009). These two problems, however, are sometimes confused. Di Paolo and De Jaegher (2007), for example, define PSM on the basis of a more basic sensemaking where enactive exchanges with the world are inherently significant. Importantly, however, they point out that sense-making happens not merely by means of an enactive, embodied movement, but also through coordinated interaction with others, and precisely this is participatory sense-making. De Jaegher and Di Paolo complain, however, that the concept of PSM is simply missing even in embodied accounts of social cognition, and such accounts could be improved if they were reoriented to PSM. Their idea, then, is "to reframe the problem of social cognition as that of how meaning is generated

Cultural practices and social roles are also important aspects that support social cognition (see Gallagher and Hutto 2008; Ratcliffe 2007). 
and transformed in the interplay between the unfolding interaction process and the individuals engaged in it" $(2007,485)$. Thus, they are interested in how aspects of social interaction affect the way participants understand each other, e.g., in dialogue how emotional attributions are influenced by temporal delay or are reciprocally constructed (497-98) - and they think of this as an example of PSM (also see Fuchs and De Jaegher 2009).

I have argued that it is much more accurate to say that PSM is a closely related, but different problem from the problem of social cognition. PSM addresses the issue of how intersubjective interaction enters into meaning constitution, and most generally the co-constitution of the meaningful world. The question that PSM addresses is: How do we, together, in a social process, constitute the meaning of the world? In contrast, the problem of social cognition is centered on the following question: How do we understand another person?

One can still say that these two problems are closely related. On the one hand, the problem of PSM is the more general problem and may include social cognition since if we are trying to make sense out of the world, that world includes other people. In this regard understanding others may be part of PSM, if in making sense of them we are also engaged interactively with them or with others. On the other hand, and in a more primary sense, it goes the other way, that is, our understanding of the world is shaped by our interactions with, and in our understanding of, other people, how they act in the world, how they value or fail to value objects, and so on. There is a certain ordering of these problems in the sense that PSM for the most part seems to presuppose that I am capable of making sense of the other person in our interactions (this is clearest in De Jaegher and Di Paolo 2007).

Despite the close relationship between the two problems, it's important to note their difference. The difference is summarized in terms of their respective targets: in the case of PSM, the world (most generally), and in the case of social cognition, other agents or persons. Understanding another person is quite different from understanding a tool, an object, a worldly event, etc. and indeed, even perceiving another person is different from perceiving a tool or an object (Gallagher 2008b). Making sense of the world together (with another person) is not the same thing as making sense of another person within our interactive relationship, even if that interactive relationship itself involves PSM. One process may contribute to the other; and indeed, both depend on interaction. PSM involves interaction with others; the meaning of the world emerges through our interaction together. In some sense, to the extent that intersubjective interaction is involved in both social cognition and PSM, we have two different questions that have a common core to their answer. Perhaps the closeness of these problems comes out best in the conceptions of joint attention and secondary intersubjectivity where our ability to see and interact with others in our everyday dealings with the world - as we use objects, navigate situations, etc. - helps us to understand their intentions, feelings, attitudes, dispositions 


\section{L'attention}

and so on. We can think of the capacities gained in joint attention and secondary intersubjectivity as contributing to how we can make sense of the world together.

\section{Interaction}

The kind of interaction found in both social cognition and PSM can best be explained from an enactive perspective. On the enactive view, as embodied agents, we do not passively receive information from our environment and then create internal representations of the world; rather, we actively participate in the generation of meaning. Thus, our world is not a pre-given external realm, it is the result of pragmatic and dynamic interchanges between agent and environment (Dewey 1896; Gallagher 1986; Thompson 2007; Varela et al. 1991). On this model, social cognition is based on social interaction.

The analyses of social interactions in shared activities, in working together, in communicative practices, and so on, show that agents unconsciously coordinate their movements, gestures, and speech acts (Issartel et al. 2007; Kendon 1990; Lindblom 2007). In communication, as we listen to another person, we coordinate our perception-action sequences; our movements are coupled with changes in velocity, direction and intonation of the movements and utterances of the speaker. Our movements are often synchronized in resonance with others, following either in-phase or phase-delayed behavior, and in rhythmic co-variation of gestures, facial or vocal expressions (Fuchs and De Jaegher 2009). Developmental studies show the very early appearance of, and the importance of, this timing and coordination in the intersubjective context $^{3}$. In still face experiments, for example, infants are engaged in a normal face-to-face interaction with an adult for 1 to 2 minutes, followed by the adult assuming a neutral facial expression. This is followed by another normal face-to-face interaction. Infants between 3 and 6 months become visibly discouraged and upset during the still face period (Tronick et al. 1978). The importance of interactive touch has also been demonstrated in the still-person effect (Muir 2002).

Murray and Trevarthen (1985) have also shown the importance of the mother's live interaction with 2-month old infants in their double TV monitor experiment where mother and infant interact by means of a live television link. The infants engage in lively interaction in this situation. When presented with a recorded replay of their mother's previous actions, however, they quickly disengage and become distracted and upset. These results have been replicated, eliminating alternative explanations such as

3. Indeed, interaction likely predates strictly intersubjective relations and can be traced to prenatal motor experience and the non-conscious motor coupling between mother and fetus (Lymer 2010). 
infants' fatigue or memory problems (Nadel et al. 1999; Stormark and Braarud 2004).

Interaction theory (IT), in contrast to the theory theory (TT) and the simulation theory of social cognition (ST) focuses on the emergence of this interactive behavior, apparent in early infancy, in processes of primary intersubjectivity. The infant's understanding of the other person is not a form of mindreading or mentalizing that targets the other's mental states (as argued by TT and ST); it is rather a perceptual and affective grasping of the meaning of other's behavior as manifested in their movements, postures, gestures, facial expressions, vocal intonations, etc. It is based on this dynamical process of interaction and dyadic coordination of embodied agents coupled to each other in perceptual and emotional ways.

This kind of interaction involves coordination but does not imply perfect synchronisation. Studies show that non-autistic infants from 3 months of age prefer slight modulations (time-delays) and imperfect contingency in responses (Gergely 2001). As De Jaegher (2008) suggests, continuous movements between synchronised, desynchronised and the states in-between, drive the process. Attunement, loss of attunement, and re-established attunement maintain both differentiation and connection. Importantly, the interaction goes beyond each participant; it results in something (the creation of meaning) that goes beyond what each individual qua individual can bring to the process. There may be just two individuals if there is no interaction; but if two individuals interact, there is something more, just as when two people dance the tango, something dynamic is created that neither one could create on their own. In this regard interaction has a certain kind of autonomy (De Jaegher and Di Paolo 2007), and neither of the participants are entirely able to completely control the interactive process, if it is truly interactive. In cases were one person is totally in control of the other person, there is no interaction in this specific sense. Indeed, this reflects a basic hermeneutical aspect of interaction interpretation of the other person, or of the world with or through the other person, always extends beyond the control of the agent, and this is the basis of learning (Gallagher 1992). Accordingly, sustained and repeated interactions build "implicit relational knowledge" and improve possibilities for greater fluency, flexibility, and further successful interactions (see De Jaegher and Di Paolo 2007, p. 496).

That these interactions are embodied, means that they are sensory-motor, perceptual, kinaesthetic, and hedonic (see Cole and Montero 2007). Movement and perception of movement (in action, but also in gestures, vocalizations, facial expressions) play a large role in constituting these interactions. In these embodied dimensions, saliency and meaning emerge. The intentions of the other person are visible in their movements. Grasping, pointing, moving towards, moving away, staying close, nodding, gazing in a certain direction, etc. - all of these things occurring in specific styles (Hobson in press) - register, often non-consciously, as inherently meaningful. For example, not only does the direction of another person's gaze indicate 
current interest in an object, their facial expression, which may reflect specific emotional content, will have an effect on the way I may come to feel about that object, and may lead to or discourage subsequent action directed towards that object (Bayliss et al. 2006; 2007; Becchio et al. 2007; 2008).

Interactions also include mutually generated intentional actions and responses that lead to a build up of meaningful action chains. One intentional movement - e.g., pointing - may motivate movement on the other's part, moving in a specific direction, reaching, grasping, moving back, handing over, taking back, and so on, creating, as Fuchs and De Jaegher indicate, "a common space" of meaning in movement. Note that this kind of action chain can also be worked into a narrative structure. This common space includes, however, not just the meanings of the other person's actions and intentions in primary intersubjectivity; that is, interaction supports not just social cognition; it also supports participatory sense-making that makes sense out of the world through our engagements with others. This begins and is most clearly manifest in the phenomenon of joint attention.

\section{Joint attention and joint action}

In joint attention, which developmentally begins to emerge around 9 months of age (Reddy 2008), I, as an experiencing subject, learn about the world through others. When we see another person look at something, or gaze in a certain direction, we automatically tend to follow their gaze to the object or the location. This is often the initiation of an instance of joint attention, which has importance for our ability to generate meaning in participatory sense-making. Not only does the direction of another person's gaze indicate current interest in an object, their facial expression, which may reflect specific emotional content, will have an effect on the way I may come to feel about that object, and it may lead to or discourage subsequent action (Bayliss et al. 2006; 2007; also Niedenthal et al. 2005; see Gallagher, in pressb). How I perceive the world, and what saliences I find there, are to some extent put in place by the gazes and actions of others. My actions with respect to the world, and with respect to others, emerge in the context set by those others. Repacholi and Meltzoff (2007; Repacholi, Olsen and Meltzoff 2006; Repacholi, Meltzoff and Olsen 2008), for example, have shown that the emotional expressions of one person while watching the action of another (showing anger or a neutral facial expression) will influence an 18-month old infant's inclination to imitate the actions of the second person (also Walden and Ogan 1988).

The interactive nature of joint attention, with respect to both social cognition and participatory sense-making, depends on a certain kind of intersubjective coordination. How should we characterize this coordination? According to Tomasello (1995), joint attention involves the coordination of attention. "In joint attention the child coordinates her attention to the object 
and the adult at the same time as the adult coordinates her attention to the same object and the child" (Tomasello 1995, 107). What exactly does it mean to coordinate attention? One view is that since attention is a psychological state, then the coordination must be a psychological coordination. In philosophy of mind the notion of psychological coordination is often framed in terms of propositional attitudes, or being in certain mental states, like belief or desire - states where we mentally recognize something to be the case. Moreover, on this view, with respect to joint attention, the object of such propositional states is the other person's mental states - i.e., we recognize or know that the other person is attending, and the other person knows that we are attending. John Campbell summarizes this view.

\begin{abstract}
There are various ways in which propositional states could be involved in coordination. Propositional states might enter into the control of attention itself and they might enter into my recognition of how my attention, or your attention, is being controlled. First, it might be that I know what you are attending to, and that this knowledge is a factor in sustaining my attention on the thing. Secondly, I might intend to attend to whatever you are attending to. And thirdly, it might be that I know that the reason I am attending to the thing is, in part, that you are attending to it. And finally, it might be that I know that the reason you are attending to the thing is, in part, that I am attending to it. (Campbell 2005, 245).
\end{abstract}

Such accounts are consistent with TT and ST conceptions of mindreading, rather than embodied interaction. I not only have to know that you are attending, but I have to know that you are capable of having such a mental state as attending to something, and that is something I have to infer or simulate. Such mindreading, as Campbell points out, "is 'off-line' in that its upshot is not permanent and it is decoupled from action" (242). Decoupled from action because TT and ST, as noted, have traditionally been cast in terms of third-person observation rather than second-person interaction.

The fact that joint attention capability develops between 9 months and 1 year of age is already problematic for TT and explicit versions of ST - that is, for any account of social cognition that depends on some kind of complex cognition or some additional step of interpretation beyond what is available perceptually and contextually. But if it is not theory or simulation that provides access to others' minds, then what? What is the nature of the perceptual and contextual factors that seemingly give us access to the other person's mental state of attention? This, however, is just the wrong way to frame the question, because once we admit that what is required for joint attention is the discernment of mental states that are not accessible and that must be inferred or simulated, then joint attention in young infants is problematic.

I have argued elsewhere that the coordination involved in joint attention, rather than involving the coordination of mental or psychological states, is primarily motoric and affective (Gallagher in press-a\&b): joint attention involves primarily a coordination of movement and affect. In contrast to TT 


\section{L'attention}

and ST, interaction theory suggests that the task is not to access interior propositional attitudes, but to perceive intentions and dispositions in the embodied behaviors, movements, facial expressions, gestures, and actions of others (even if there is an undeniable interior dimension of experience and affect associated with these externalities). Joint attention decoupled from action, and specifically inter-action, is the rare case (perhaps the case in which my connection or coordination with the other person breaks down).

Consider the following phenomenological example, from Campbell (2005). I find myself in a pasture looking at some cattle that start to move toward me. As the individual cow moves it seems to be checking that its fellow cows are coming along. Campbell seems to suggest that the cows themselves are involved in a joint attentional situation. In any case, my own response is not to try to get into their minds, or to work out some set of propositional attitudes that I attribute to them. Rather, my understanding of their joint attention on a particular object (me, in this case) and my own attempt to make sense out of what they are doing immediately translates into movement on my part.

Furthermore, if I try to discern whether they are going to change direction before they reach me, I don't try to mindread their mental states, I try to see it in their movements - or in the movement of the herd as a whole - and this in reference to the shape of the field and the possibilities for their moving this way or that. My attention to what and where they are attending sets my feet in motion.

If we consider a variation of this setting, I think we can see that the attention that I share with other humans involves nothing more than something like this. If, for example, my friend and I happen to be in the pasture looking at a slow stampede coming towards us, if we catch each other's eye, as they say, if she grabs my arm and yells and we start to run, is there anything more to the coordination that we have to explain? Do I have to consider her beliefs and desires? Do I need folk psychology or do I need to employ a theory to understand why someone grabs another person's arm? Do I need to simulate my friend's situation or what she might be thinking? No, the kind of knowledge I need is a very practical kind that is based on my ongoing perception. Notice that in this example we are engaged in both social cognition (I am making sense out of my friend's behavior) and participatory sense making (together we are jointly attending to and making sense out of the cows" behavior).

Perhaps a better example can be found in empirical studies conducted by Lindblom (2007; see Lindblom and Ziemke 2007; 2008). In a frame-by-frame analysis of video images from episodes of spontaneous social interaction captured in situ, Lindblom was able to show the precise dynamics of interaction in joint attention during a novel but well-defined task. The task is to lift a very young horse (filly) onto her legs. The individual, Bob, who initiates the action draws the attention of his two colleagues, not by his vocal instructions, but by his movement toward the horse, his hand-claps and 
encouraging words to the horse. There is a large amount of background knowledge about horses that enter into the dynamic. "The situation at hand is obvious, the fact that the filly is unable to rise by herself is obvious, and everybody knowing it is not healthy for a horse to lay down for too long [leads to the formation of a joint intention to lift the horse]" (Lindblom 2007, 227). They also know that one person on his own cannot lift the filly. Two ranch workers come to Bob's aid, and from that point they set about lifting the horse with very little vocal communication. Rather bodily actions, facial expression, gaze direction, tone of voice, bodily posture, and gesture, communicate the specific movement intentions among the group as they work. Joint attention is maintained through such bodily and communicative movements, and it leads directly to a complex joint action that is guided by the continuing movements, postures, gestures, etc. of all three participants. Here is the sequence of events.

At first, Bob is standing next to the filly and begins to bend down at the same time as the filly begins an attempt to rise. As Lindblom notes, it is difficult to say who is influencing who at this point. The filly might notice Bob's downward movement as an intention to help, or Bob might be grasping the filly's intention to rise, and for that reason he bends down to assist her. "Together they create a co-regulated activity with the intention to 'get up'" (227).

This first lifting attempt fails and his two colleagues rush over "with big strides as well as almost in step", but with attention directed toward the filly. Bob, who is just beginning another attempt, notices their approach, and utters "Come on". Together they take up positions for the actual lift. This attempt also fails, "seemingly because they did not really cooperate with each other or did not know exactly how to perform the joint action of lifting, and consequently the unregulated interaction, lasting about 5 seconds, comes to nothing" (229).

The men then back away to assess the situation. An onlooker suggests a strategy of grasping each other's hands from underneath the filly. One of the men then aligns his bodily position opposite Bob to indicate readiness to try the strategy. Bob motions for the onlooker to join them (to provide a partner for the third man), indicating where she should locate herself by his gestures.

Bob then demonstrates by way of a lifting gesture: "he lowers his upper body and hands slightly, and then he continues the whole gesture upwards..." illustrating both the common consensus and how the attempt will be made (231). Before Bob lowers his hands, one of the other men who has been looking at Bob, "starts to make a lifting gesture, which is slightly different, as a way of sharing Bob's idea of how to lift, as well as indicating that he actually has understood [from his perspective] what to do in the next try" (232). This gesture combines elements of a first-person perspective, lifting his hands as he would in the action - indicating he understands his role in the process - and then a second-person perspective - he ends by 


\title{
L'attention
}

overlapping his hands, representing how his hand will be in relation to Bob's hand.

The following action, with Bob and one co-worker joining hands under the midsection of the filly, the other man at the hind quarter, and a fourth person joining the group and pulling the horse up from the front, is perfectly coordinated and successful.

This is an example of the human capacity to engage in joint attention, joint action, and participatory sense-making. A common intentionality emerges among the individuals as they enter into the interaction involved in a specific task. This interaction is carried out primarily in spatially and temporally coordinated movements that include action-oriented positioning and posture, and communicative gesture. To understand how this process works, one needs to take the entire group as the unit of analysis. Their shared understanding emerges from a set of embodied movements and actions in the specific context of what they were doing, and it is irreducible to any set of mental states in one individual or even the collection of mental states found in all of them. The action, and the meaning of the action, transcends any one individual; it is generated in the interaction required for the outcome. The joint action, as Lindblom indicates $(2007,237)$, is a distributed and collective phenomenon.

\section{Conclusion}

I have argued that both social cognition and participatory sense-making, in cases of joint attention and joint action, depend primarily on movement bodily movement and posture, taking up a relevant position vis a vis the other, gestures, facial expressions, vocal intonations, communicative actions, and so forth - and not on mindreading abilities that focus on the other person's mental states and attentional status. Evidence can be found for this interactive approach in an extensive array of developmental studies, in phenomenology, and in empirical observations made in the field.

\author{
Shaun Gallagher \\ Institute of Simulation and Training \\ University of Central Florida \\ School of Humanities \\ University of Hertfordshire
}

\section{References}

Baron-Cohen, S. 1991. Precursors to a theory of mind: Understanding attention in others. In A. Whiten (ed), Natural theories of mind: Evolution, development and simulation of everyday mindreading. (pp. 233-251). Cambridge, MA, US: Basil Blackwell. 
Bayless, A.P., Paul, M.A., Cannon, P.R. and Tipper, S.P. 2006. Gaze cuing and affective judgments of objects: I like what you look at. Psychonomic Bulletin E Review 13 (6), 1061-1066

Bayliss, A.P. et al. (2007) Affective evaluations of objects are influenced by observed gaze direction and emotional expression. Cognition 104: 644-653

Becchio, C., Bertone, C. and Castiello, U. 2008. How the gaze of others influence object processing. Trends in Cognitive Sciences (12) 7: 254-58.

Becchio, C. et al. 2007. Motor contagion from eye gaze. The case of autism. Brain 130: 2401-2411

Campbell, J. 2005. Joint attention and common knowledge. In N. Eilan, C. Hoerl, T. McCormack, and J. Roessler (eds.), Joint attention: communication and other minds (287-97). Oxford: Oxford University Press.

Cole, J. \& Montero, B. 2007. Affective proprioception. Janus Head 9 (2): 299-317.

De Jaegher, H., and Di Paolo, E. (2007) Participatory Sense-Making: An enactive approach to social cognition. Phenomenology and the Cognitive Sciences 6, 485-507.

De Jaegher, H., Di Paolo, E. and Gallagher, S. (2010). Does social interaction constitute social cognition? Trends in Cognitive Sciences. Published online 30 July 2010. 10.1016/j.tics.2010.06.009

Dewey, J. 1896. The reflex arc concept in psychology. Psychological Review 3: 357-370.

Fuchs, T. and De Jaegher, H. 2009. Enactive intersubjectivity: Participatory sense-making and mutual incorporation. Phenomenology and the Cognitive Sciences 8:465-486

Gallagher, S. (in press-a). Interactive coordination in joint attention. In A. Seeman (ed.), Joint Attention: Developments in Philosophy of Mind, Developmental and Comparative Psychology, and Cognitive Science. Cambridge, MA: MIT Press.

Gallagher, S. (in press-b). Movement and emotion in joint attention. In S. Flach and J.G. Soeffner (eds.), Motion and Emotion.

Gallagher, S. 2009. Two problems of intersubjectivity. Journal of Consciousness Studies 16 (6-8): 289-308

Gallagher, S. 2008a. Understanding others: Embodied social cognition. In P.C. Garzón (ed.), Elsevier Handbook of Embodied Cognitive Science (439-52). London: Elsevier.

Gallagher, S. 2008b. Inference or interaction: Social cognition without precursors. Philosophical Explorations 11 (3): 163-73.

Gallagher, S. 2005. How the Body Shapes the Mind. Oxford: Oxford University Press.

Gallagher, S. 1992. Hermeneutics and Education. Albany: State University of New York Press.

Gallagher, S. and Hutto, D. 2008. Understanding others through primary interaction and narrative practice. In: J. Zlatev, T. Racine, C. Sinha and E. Itkonen (eds). The Shared Mind: Perspectives on Intersubjectivity (17-38). Amsterdam: John Benjamins. 


\section{L'attention}

Gergely, G. 2001. The obscure object of desire: "Nearly, but clearly not, like me": Contingency preference in normal children versus children with autism. Bulletin of the Menninger Clinic 65: 411-26.

Hobson, R.P. (in press). Autism and the self. In S. Gallagher (ed). Oxford Handbook of the Self. Oxford: Oxford University Press.

Issartel, J., Marin, L., \& Cadopi, M. 2007. Unintended interpersonal coordination: “Can we march to the beat of our own drum?". Neuroscience Letters 411: 174-179.

Kendon, A. 1990. Conducting interaction: Patterns of behavior in focused encounters. Cambridge: Cambridge University Press.

Lindblom, J. 2007. Minding the Body: Interacting socially through embodied action. Linköping Studies in Science and Technology. Dissertation No. 1112

Lindblom, J. and Ziemke, T. 2007. Embodiment and social interaction: implications for cognitive science. In T. Ziemke, J. Zlatev \& R. Frank (Eds.), Body, language, and mind: Embodiment, 1, (pp.129-162). Berlin: Mouton de Gruyter.

Lindblom, J. and Ziemke, T. 2008. Interacting Socially through Embodied Action. In. F. Morganti, A. Carassa, G. Riva (Eds.). Enacting Intersubjectivity: A Cognitive and Social Perspective on the Study of Interactions (pp. 49-63). Amsterdam, IOS Press.

Lymer, J. 2010. The phenomenology of the maternal-foetal bond. Doctoral thesis. School of English, Literatures and Philosophy. University of Wollongong, Australia.

Muir, D.W. 2002. Adult communications with infants through touch: The forgotten sense. Human Development, 45, 95-99.

Murray, L., and Trevarthen, C. (1985) Emotional regulation of interactions between 2month-olds and their mothers. In Social Perception in Infants (Field, T.M., and Fox, N.A., eds), 177-197, Ablex

Nadel, J., et al. 1999. Expectancies for social contingency in 2-month-olds Developmental Science 2: 164-173

Niedenthal, P.M., Barsalou, L.W., Winkielman, P., Krath-Gruber, S. and Ric, F. 2005. Embodiment in attitudes, social perception, and emotion. Personality and Social Psychology Review 9 (3): 184-211.

Ratcliffe, M.J. 2006. Rethinking Commonsense Psychology: A Critique of Folk Psychology, Theory of Mind and Simulation. Basingstoke: Palgrave Macmillan.

Reddy, V. 2008. How Infants Know Minds. Cambridge, MA: Harvard University Press.

Repacholi, B.M., \& Meltzoff, A.N. (2007). Emotional eavesdropping: Infants selectively respond to indirect emotional signals. Child Development 78, 503-521.

Repacholi, B.M., Meltzoff, A.N., \& Olsen, B. 2008. Infants' understanding of the link between visual perception and emotion: "If she can't see me doing it, she won't get angry". Developmental Psychology 44: 561-574

Repacholi, B., Olsen, B.R. and Meltzoff, A.N. 2006. How infants integrate attentional and emotional cues in order to regulate their imitative responses." Paper presented 
at the annual meeting of the XVth Biennial International Conference on Infant Studies, Westin Miyako, Kyoto, Japan (http://www.allacademic.com/meta/ p93887_index.html)

Stormark, K.M., and Braarud, H.C. 2004. Infants' sensitivity to social contingency: A "double video" study of face-to-face communication between 2- and 4-montholds and their mothers. Infant Behavior and Development 27: 195-203

Tomasello, M. 1995. Joint attention as social cognition. In C. Moore \& P.J. Dunham (Eds.), Joint Attention: Its Origin and Role in Development, (pp. 103-130). Hillsdale, N.J.: Lawrence Erlbaum.

Trevarthen, C. 1998. The concept and foundations of infant intersubjectivity. In S. Braten (ed.), Intersubjective Communication and Emotion in Early Ontogeny. Cambridge: Cambridge University Press. 15-46.

Trevarthen, C.B. 1979. Communication and cooperation in early infancy: A description of primary intersubjectivity. In M. Bullowa (ed.), Before Speech. Cambridge: Cambridge University Press.

Trevarthen, C. and Hubley, P. 1978. Secondary intersubjectivity: Confidence, confiding and acts of meaning in the first year. In A. Lock (ed.), Action, Gesture and Symbol: The Emergence of Language (pp. 183-229). London: Academic Press.

Tronick, E., Als, H., Adamson, L., Wise, S., \& Brazelton, T.B. 1978. The infants' response to entrapment between contradictory messages in face-to-face interactions. Journal of the American Academy of Child Psychiatry 17: 1-13.

Walden, T.A., \& Ogan, T.A. 1988. The development of social referencing. Child Development, 59, 1230-1240. 